Abstract 24 Table 1 Demographics and co-morbidities of cardiac arrest patients presenting on weekdays and weekends

\begin{tabular}{|c|c|c|}
\hline & Weekday & Weekend \\
\hline $\mathrm{N}(\%)$ & $3892(81.0)$ & 919(19.0) \\
\hline Mean age $\pm S . D$ (years) & $67.7 \pm 16.6$ & $67.4 \pm 17.5$ \\
\hline Male, \% & 55.4 & 54.1 \\
\hline Mean Length of Hospital stay $\pm S . D$ (days) & $9.25 \pm 23.8$ & $10.38 \pm 22.1$ \\
\hline \multicolumn{3}{|l|}{ Co-morbidities } \\
\hline Mean Charlson Index & 1.52 & 1.33 \\
\hline Heart Failure \% & 21.4 & 20.4 \\
\hline IHD\% & 38.4 & 37.1 \\
\hline Lung Cancer \% & 2.2 & 1.8 \\
\hline Breast Cancer \% & 1.6 & 1.3 \\
\hline Colon Cancer \% & 1.4 & 0.7 \\
\hline Cerebrovascular Disease \% & 6.4 & 6.3 \\
\hline COPD \% & 15.0 & 12.0 \\
\hline CKD \% & 9.4 & 7.7 \\
\hline Dementia \% & 4.7 & 2.6 \\
\hline Pneumonia \% & 14.7 & 14.4 \\
\hline \multicolumn{3}{|l|}{ Outcomes } \\
\hline Crude 30 day mortality $\%$ & $25.4^{*}$ & $32.8^{*}$ \\
\hline Crude 1 year mortality \% & $41.0^{*}$ & $44.3^{*}$ \\
\hline
\end{tabular}

*cox regression analyses showed no significant differences in mortality between weekend and weekday presentation

\section{QTC INTERVAL RESOLUTION IN SURVIVORS OF OUT OF HOSPITAL CARDIAC ARREST WITHIN A TERTIARY CENTRE IN THE UK}

${ }^{1}$ Alexander Gall", ${ }^{1}$ Aishwarya Anilkumar, ${ }^{1}$ Emily Moore, ${ }^{2}$ Eva Sammut, ${ }^{2}$ Palash Barman. ${ }^{1}$ Bristol Heart Institute; ${ }^{2}$ University of Bristol/Bristol Heart Institute

\subsection{6/heartjnl-2019-BCS.24}

Introduction In the UK there are approximately 60,000 out of hospital cardiac arrests (OHCA) annually. Post arrest, a prolonged QTc interval (QTc) on the electrocardiogram (ECG) has been described1. It is unclear whether this is transient, an effect of therapeutic hypothermia, or a substrate of underlying condition. This observational study aims to investigate the incidence and behaviour of prolonged QTc post OHCA.
Methods A retrospective review of patient casenotes was performed on survivors of OHCA admitted to the Bristol Heart Institute (BHI), from March 2014 to November 2015. ECGs recorded throughout the admission were reviewed and categorised into time frames post OHCA. The QT interval was measured manually and QTc calculated using Bazett's formula. Statistical analyses were performed using Excel and Graphpad Prism.

Results We identified 106 consecutive OHCA survivors presenting at our centre. On admission, the median QTc across the cohort was $495 \mathrm{~ms}$ (20.91 SEM, range 376 - 745), male $492 \mathrm{~ms}$ (8.5 SEM), female 516ms (22.0 SEM). All patients underwent emergency angiography. Subsequently, 105 patients were taken to ITU with the majority (101 patients, 96.2\%)

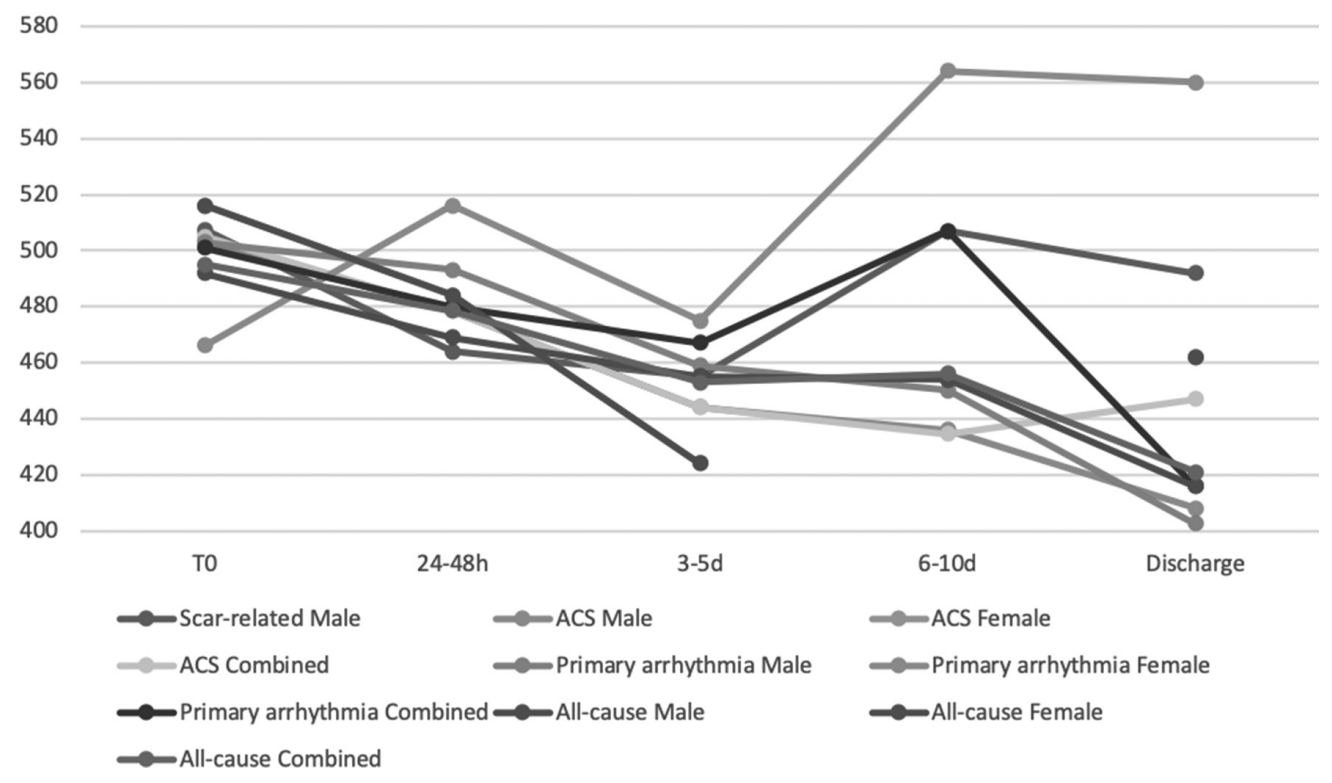

Abstract 25 Figure 1 


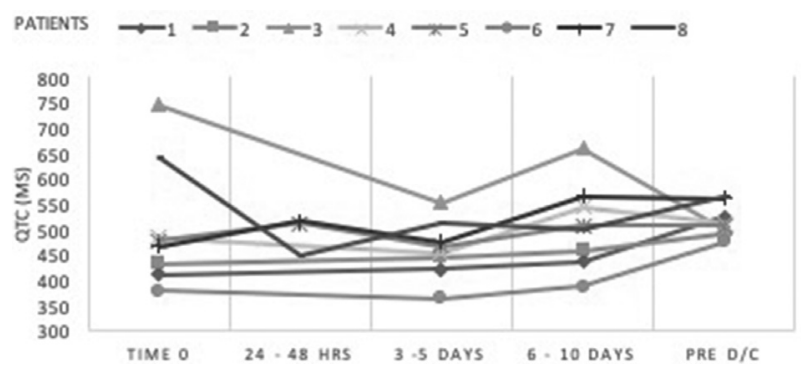

Abstract 25 Figure 2

undergoing targeted temperature management (TTM) to 32$34 \mathrm{C} \hat{\mathrm{E}}$ for 24 hours.

Of 106 individuals with OHCA, 58 (55\%) were due to acute coronary syndrome (ACS), 20 (19\%) were scar related, $15(14 \%)$ were due to a primary arrhythmia, and $13(12 \%)$ were non-cardiac or other. 79/106 (75\%) had a prolonged QTc post cardiac arrest, defined as $>460 \mathrm{~ms}$ (males) or $>470 \mathrm{~ms}$ (females). Of these, 14 were excluded due to incomplete data, resulting in a final cohort of 65 patients. Among patients with a prolonged QTc on admission, there was no significant difference according to cause of OHCA.

From immediately post-arrest (T0) to discharge, the median QTc decreased from 495ms (20.9 SEM, range 376 $745 \mathrm{~ms})$ to $421 \mathrm{~ms}$ (11.7 SEM, range 360 - 561ms). This did not vary significantly by cause of arrest (figure 1). For the ACS group, mean QTc decreased from $50511.8 \mathrm{~ms}$ (range 376 - 745 , male $503.512 .9 \mathrm{~ms}$, female $51634.4 \mathrm{~ms}$ ) to 447 $15.0 \mathrm{~ms}$ (range 278 - 561, male $40815.7 \mathrm{~ms}$, female 462 $37.8 \mathrm{~ms}$ ). The scar related group decreased from 507.5 $21.3 \mathrm{~ms}$ (range 423 - 745, all male) to $49218.8 \mathrm{~ms}$ (range 400 - 511). In those who sustained an OHCA due to primary arrhythmia the mean QTc was $5019.7 \mathrm{~ms}$ (range 456 $536 \mathrm{~ms}$, male $50310.2 \mathrm{~ms}$ ). The one female in this group saw an increase in QTc from $466 \mathrm{~ms}$ on admission to $560 \mathrm{~ms}$ at discharge and was subsequently diagnosed with congenital LQT2 syndrome.

\section{A}

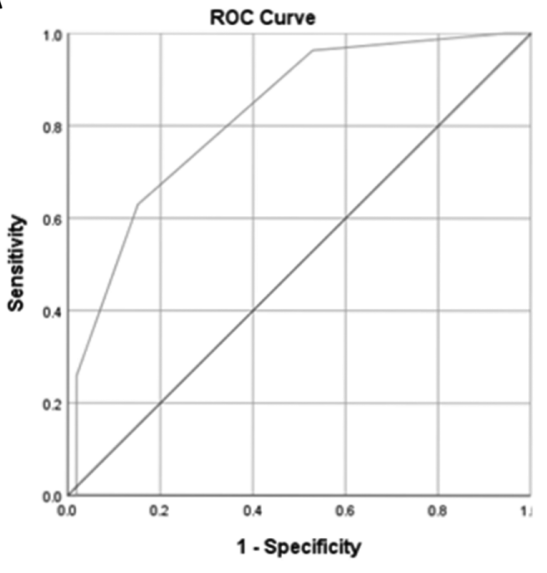

Diagonal segments are produced by ties.
Despite most patients demonstrating an improvement in QTc, a prolonged QTc was persistent in eight (12.3\%) patients (figure 2).

Conclusion QTc interval is prolonged in a large proportion of patients following cardiac arrest, however this resolves in the majority pre-discharge. Despite concerns regarding the safety of TTM in a cohort who often have a prolonged QTc, we have shown resolution of the QTc in most despite nearly all patients receiving TTM.

In our cohort, only one patient was found to have congenital long QT syndrome.

Conflict of Interest None

\section{PREVALENCE AND RISK FACTORS FOR ATRIAL FIBRILLATION IN BETA-THALASSAEMIA MAJOR: UK SPECIALIST CARDIO-HAEMATOLOGY CLINIC EXPERIENCE AND DEVELOPMENT OF A PREDICTIVE AF RISK SCORING SYSTEM (CH4ADI)}

${ }^{1}$ Robert Bell", ${ }^{1}$ Tsz Chau, ${ }^{1}$ Munashe Veremu, ${ }^{1}$ Amna Abdel-Gabir, ${ }^{2}$ Ratna Chatterjee, ${ }^{1}$ John Porter, ${ }^{1}$ Malcolm Walker. ${ }^{1}$ University College London; ${ }^{2}$ University College London Hospital

\subsection{6/heartjnl-2019-BCS.25}

Introduction The prognosis of Beta-thalassemia major (TM) has been transformed in recent decades, revealing new management challenges including atrial fibrillation (AF). While recognised as a common finding, neither the prevalence nor risk factors for developing $\mathrm{AF}$ in this patient cohort are well characterised.

Methods We undertook a retrospective cross-sectional analysis of TM patients under review in our specialist-lead, cardio-haematology clinic at UCLH. Two cohorts were established: 80patient derivation and a 189-patient validation group. Multivariate analysis was performed, deriving odds ratios (OR) to identify potential risk factors to derive a risk score that was then tested using the Receiver Operator Characteristic (ROC), and verified within the validation cohort.

Results Within the 80 patient derivation cohort, aged 20-57 years (mean 38.3, median 38), 27 (33.8\%) had AF,

B

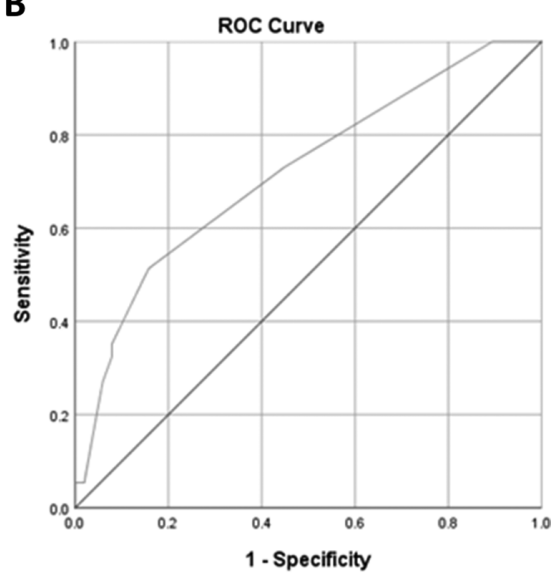

Diagonal segments are produced by ties 